\title{
DIÁLOGOS SOBRE ALFABETIZAÇÃO DE JOVENS, ADULTOS E IDOSOS NO ÂMBITO DO CFP/UFRB
}

\section{Dialogues on youth, adults and elderly literacy under CFP/UFRB}

\author{
Maria Eurácia Barreto de Andrade - UFRB/BA, Brasil \\ Gilselia Macedo Cardoso Freitas - UFRB/BA, Brasil
}

Andreia Barbosa dos Santos - UFRB/BA, Brasil

\begin{abstract}
RESUMO: Este artigo debruça-se sobre a experiência vivenciado na unidade temática no âmbito do Centro de Formação de Professores, da Universidade Federal do Recôncavo da Bahia. Para tanto, o objetivo que mobilizou o trabalho foi compartilhar a experiência vivenciada no componente "Diálogos sobre alfabetização de jovens, adultos e idosos" e seus impactos para a comunidade acadêmica. Nesta perspectiva, as referências básicas que respaldaram o trabalho foram pautadas em Freire (1992; 2003), Garcia (2007), Giroux (1992) e Benincá (2002). O percurso metodológico, pautado na metodologia da práxis Benincá (2002) foi atravessado por questões da teoria/prática, ensino/pesquisa em constante consonância e apresentaram-se de forma interdependentes e indissociáveis nos mais diversos momentos formativos. $\mathrm{O}$ produto final exigiu dos participantes lançarem mão das reflexões teórico-conceituais estudadas para a produção do trabalho prático que constituiu na pesquisa e edição de um vídeo documentário com pessoas (jovens, adultas ou idosas) sobre o seu processo de alfabetização. Os resultados apontaram que os impactos da experiência vivenciada ultrapassaram os limites da Universidade, contemplando outros espaços e sujeitos, por meio de um trabalho alicerçado no diálogo e na colaboração, partindo dos sujeitos em um estrito processo de humanização.
\end{abstract}

Palavras-chave: Alfabetização. Educação de Jovens, Adultos e Idosos. Formação Docente. Processos de Alfabetização.

ABSTRACT: This article focuses on the experience of the thematic unit within the Center for Teacher Training, Federal University of Recôncavo da Bahia. Therefore, the objective that mobilized the work was to share the experience lived in the component "Dialogues on literacy of young people, adults and the elderly" and its impacts on the academic community. In this perspective, the basic references that supported the work were Freire (1992; 2003), Garcia (2007), Giroux (1992) and Benincá (2002). The methodological path was crossed by questions of theory / practice, teaching / research in constant consonance and presented in an interdependent and inseparable way in the most diverse formative moments, based on the praxis methodology (Benincá, 2002). The final product required participants to make use of the theoretical and conceptual reflections studied for the production of practical work that consisted in researching and editing a documentary video with people (young, adult or elderly) about their literacy process. The results showed that the impacts of the lived experience exceeded the University limits, contemplating other spaces and subjects, through a work based on dialogue and collaboration, starting from the subjects in a strict process of humanization. 
Keywords: Literacy. Youth, Adult and Elderly Education. Teacher training. Literacy Processes.

\section{INTRODUÇÃO}

Não se pode negar que a educação ${ }^{1}$ ocupa lugar de destaque em qualquer ação humana, sendo, para além de um direito de todo cidadão, exigência para a construção de uma sociedade mais justa e humanamente organizada. Mesmo se constituindo enquanto um direito básico e considerando os esforços investidos, sobretudo pelos movimentos e organizações sociais, o nosso país enfrenta inúmeros desafios do ponto de vista da busca pela superação de entraves históricos, como por exemplo, o analfabetismo entre as pessoas jovens, adultas e idosas.

Dialogar sobre a alfabetização de pessoas jovens, adultas e idosas é urgente e requer uma ampla problematização com olhar sobre os seus processos históricos e os movimentos de luta, marcados por avanços e retrocessos, além de tencionar discussões sobre o papel que o analfabetismo cumpre na sociedade de classe. Esta é uma reflexão necessária e emergente, sobretudo no âmbito acadêmico nos cursos de formação de professores para que o debate sobre os sujeitos, os contextos e o lugar ocupado pelos jovens, adultos e idosos não alfabetizados seja ampliado com a intenção de romper com o seu caráter assistencialista e, ao mesmo tempo, na perspectiva contra-hegemônica, avançar na luta pela superação da dualidade construída historicamente na educação brasileira.

Partindo desse pressuposto, o curso de Pedagogia, do Centro de Formação de Professores, da Universidade Federal do Recôncavo da Bahia, contempla, no rol dos estudos optativos, o componente curricular "Diálogos sobre Alfabetização de Jovens, Adultos e Idosos" que busca um amplo estudo, compreensão, debate, problematização e reflexão acerca da alfabetização como um direito, dos fundamentos da alfabetização de pessoas jovens, adultas e idosas, das concepções e práticas educativas para os sujeitos não escolarizados e a alfabetização na perspectiva da Educação Popular, tendo como

Educação, Psicologia e Interfaces, Volume 4, Número 1, p. 64-75, Janeiro/Março, 2020.

ISSN: 2594-5343. DOI: https://doi.org/10.37444/issn-2594-5343.v4i1.181 
desafio, superar concepções e práticas conformadoras à ordem capitalista e articular a modalidade na luta por transformações estruturais na sociedade brasileira.

Este artigo propõe apresentar reflexões sobre a experiência vivenciada em duas edições do componente em pauta, evidenciando os caminhos trilhados, as reflexões tecidas no processo e os resultados alcançados. Para tanto, o objetivo que mobilizou o trabalho foi compartilhar a experiência vivenciada no âmbito do componente "Diálogos sobre Alfabetização de Jovens, Adultos e Idosos" e seus impactos para a comunidade acadêmica.

A intenção é que esta experiência contribua significativamente para a ampliação do debate acerca da alfabetização de Jovens, Adultos e Idosos, a fim de repensar o lugar ocupado, os sujeitos inseridos e seus contextos de vida e escolarização, de modo que possa avançar na luta contra os entraves construídos historicamente e buscar estratégias de resistência contra a retirada de direitos conquistados.

\section{2 - PERCURSO METODOLÓGICO: CAMINHOS TRILHADOS NA APROXIMAÇÃO COM A REALIDADE OBJETIVA}

Do ponto de vista metodológico a metodologia da práxis foi o fundamento orientador das ações dos sujeitos envolvidos nesta experiência (BENINCÁ, 2002). Isso porque, a práxis pedagógica possibilita a (re)significação das práticas, a transformação do cotidiano educacional, tendo como referência principal os sujeitos e suas reais possibilidades de pensar e modificar a própria realidade. Foi exatamente acreditando no sujeito e na possibilidade de mudança do seu universo social, que a metodologia da práxis foi adotada neste trabalho.

Para tanto, apostando na práxis enquanto elemento metodológico do processo, buscamos realizar um trabalho partindo dos sujeitos e suas trajetórias de vida e escolarização. Desta modo, do ponto de vista do processo, foi priorizado um trabalho que buscasse romper com a dicotomia teoria/prática, ensino/pesquisa, pesquisa/extensão por meio de uma prática em que estes campos estivessem em estreita articulação e se constituíssem de forma interdependentes.

Desta forma ensino, pesquisa e extensão, campos que sustentam o trabalho da Universidade, foram contemplados de forma dialógica e relacional nos diferentes momentos: discussões teórico-conceituais no âmbito da Universidade, com reflexões,

Educação, Psicologia e Interfaces, Volume 4, Número 1, p. 64-75, Janeiro/Março, 2020. 
debates e problematizações sobre a alfabetização de pessoas jovens, adultas e idosas; pesquisa com sujeitos não alfabetizados ou em processo de alfabetização, articulando as suas trajetórias de vida e as reflexões teóricas estudadas, tendo como elemento sistematizador e produto da pesquisa a produção de um vídeo documentário, além disso, o seminário de extensão contemplando a comunidade acadêmica, comunidade externa, professores e pesquisadores da área.

Todos estes momentos (ensino, pesquisa e extensão), buscaram contemplar teoria/prática e ensino/pesquisa/extensão de forma articulada. Nesta perspectiva, a metodologia da práxis foi priorizada por considerarmos que é capaz de promover a transformação da situação atual no que se refere à educação de pessoas jovens, adultas e idosas, tendo como principais bases e atores os sujeitos envolvidos.

\section{REFLEXÕES E PROBLEMATIZAÇÕES SOBRE O PROCESSO: NOTAS SOBRE O DEBATE}

\section{1- "REFLEXÕES SOBRE ALFABETIZAÇÃO E PROCESSOS DE EMANCIPAÇÃO HUMANA: LEITURA DE MUNDO, LEITURA DE SI”}

As reflexões tecidas e construídas sobre alfabetização na experiência aqui relatada tomam os processos de emancipação humana a partir das obras de teóricos clássicos e consabidos da educação popular e da alfabetização de jovens, adultos e idosos num atravessamento epistemológico sustentado nas obras de Paulo Freire. Ainda, situa-se numa conjuntura interdisciplinar o componente curricular "Diálogos sobre Alfabetização de Jovens, Adultos e Idosos”, pois é atingido pela tríade que sustenta a universidade nas dimensões do ensino, da pesquisa e da extensão, conforme mencionado anteriormente. Nesse sentido a proposta transcendeu o espaço da sala de aula e da oferta de um componente meramente acadêmico para se aproximar e ouvir a comunidade.

Desse modo, os conceitos priorizados foram aqueles que atendem a perspectiva crítica de educação e dialoga com a alfabetização da classe trabalhadora, sobretudo no reconhecimento do direito universal à alfabetização e acesso aos bens produzidos pela humanidade. Para GIROUX (1992):

Educação, Psicologia e Interfaces, Volume 4, Número 1, p. 64-75, Janeiro/Março, 2020.

ISSN: 2594-5343. DOI: https://doi.org/10.37444/issn-2594-5343.v4i1.181 
É essencial, na abordagem que Freire faz da alfabetização, uma relação dialética dos seres humanos com o mundo, por um lado, e com a linguagem e com a ação transformadora, por outro. ...é inerentemente, um projeto político no qual homens e mulheres afirmam seu direito e sua responsabilidade não apenas de ler, mas também de reconstituir sua relação com a sociedade mais ampla. Neste sentido, a alfabetização é fundamental para erguer agressivamente a voz de cada um como parte de um projeto mais amplo de possibilidade... (p. 7)

Esse projeto político emancipador a que se refere Giroux está sustentado no desenvolvimento do conteúdo emancipador de suas ideias numa pedagogia concreta e prática. Para tanto e para início das reflexões advindas no exercício de um projeto emancipador, exige-se recorrer ao pensamento de Gramsci onde considera a alfabetização uma prática social historicamente vinculada por configurações de conhecimento e poder, como também de luta política e cultural pela linguagem e pela experiência. Assim na dimensão da alfabetização crítica, GIROUX (1992) entende que deve

[...] ser encarada como uma construção social que está implícita na organização da visão histórica do individuo, o presente e o futuro; além disso, a noção de alfabetização precisava alicerçar-se num projeto ético e político que dignificasse e ampliasse as possibilidades de vida e de liberdade humanas. Em outras palavras, a alfabetização, como construto social, devia radicar-se em um espírito de crítica e num projeto de possibilidade que permitisse às pessoas participarem da compreensão e da transformação da sociedade. ( p.2).

O conceito de alfabetização em Paulo Freire parte de anos de uma práxis de alfabetização voltada para a relação dialética dos seres humanos com o mundo e o tema alfabetização como projeto político emancipador. Nessa esteira, o modelo freiriano é uma proposta de alfabetização emancipadora. O processo de alfabetização com enfoque libertador não se limita ao ato mecânico e repetitivo de ler e escrever, ao aprender a dizer a palavra se aprende a ler o mundo, sendo enfatizado por Freire (1996) que não se deve ensinar só a leitura da palavra, ou só a leitura do mundo, mas as duas, porque são dialeticamente solidárias.

Para o estudioso cubano Garcia (2007), as variadas propostas de alfabetização devem promover a formação de uma consciência libertadora e uma maior compreensão política de como abordar os problemas estruturais de cada país, a fim contribuir com a sua transformação. Garcia (2007) julga que os Estados têm papel preponderante na

Educação, Psicologia e Interfaces, Volume 4, Número 1, p. 64-75, Janeiro/Março, 2020. 
educação do seu povo e devem encarar esta tarefa com dedicação e não simplesmente como uma ação da gestão do poder para consolidar a exploração e dependência econômica e enfatizando que a educação é um direito e se encontra dentro da Declaração Universal dos Direitos Humanos.

Portanto, a alfabetização é defendida numa abordagem libertadora e emancipatória, pensada a partir do que postula a teoria paulofreiriana num contexto popular coerente com o ato político que é ao mesmo tempo pedagógico. Essa prática contribui para a construção de novas relações humanas de geração, gênero e etnia, formando pessoas capazes de respeitar as diversas culturas, de resignificar e valorizar sua identidade.

É nesse contexto que as reflexões sobre alfabetização e processos de emancipação humana nos sinalizam a leitura de mundo e a leitura de si. Ao ler o mundo lê-se a realidade objetiva e cria-se possibilidades de transformação social. A leitura de si mesmo potencializa a travessia da consciência ingênua para uma consciência crítica.

\section{2 - A FORMAÇÃO DE PROFESSORES NA PERSPECTIVA DA EDUCAÇÃO POPULAR: "EU NÓS"}

A Formação de Professores tem sido um dos grandes desafios de nossa sociedade. Tratar de processos de educação dentro de uma Universidade Pública no interior do país é, de fato, um convite para pensarmos novas possibilidades. Nessa perspectiva consideramos a Educação Popular tão pertinente aos processos educacionais na graduação do curso de Pedagogia.

A Educação Popular está muito longe de seu conceito vulgar: "educação para os pobres". Essa concepção está extremamente ultrapassada. A Educação Popular traz em seu peito, a luta dos movimentos sociais pelo direito à educação, a terra, ao direito de produzir e viver com dignidade. Forjada na luta, traz em si mulheres e homens destemidos e de cabeça erguida visto que é processo de Formação Humana.

Não nascemos humanos, nos tornamos humanos dentro de processos históricos, sociais, culturais, econômicos, políticos e espirituais. Somos uma existência entre tantas outras. Somos uma existência com consciência de que temos um começo, meio e fim.

Educação, Psicologia e Interfaces, Volume 4, Número 1, p. 64-75, Janeiro/Março, 2020.

ISSN: 2594-5343. DOI: https://doi.org/10.37444/issn-2594-5343.v4i1.181 
Sabemos da morte e ela nos cerca todos os dias, nos envolve e nos abraça todas as noites. Renascemos a cada amanhecer. Renascemos mais ou menos humanos.

A Educação Popular nos convida a pensar os movimentos de vida e de morte necessários para nosso crescimento enquanto humanos. É uma educação que não nega os processos históricos, os conflitos, as contradições, as emoções e sentimentos. É a educação que abraça e acolhe gente como gente e em sendo gente se constitui cada dia mais gente, cada dia mais humano. A educação "de nós, com os nossos, dos nossos, conosco".

No curso de licenciatura em Pedagogia da Universidade Federal do Recôncavo da Bahia a Educação popular tem sido construída a passos curtos, com cuidado e muito respeito aos movimentos individuais e coletivos das e dos discentes do curso. Nessa perspectiva, um processo formativo na graduação tem existência e resistência, ambas em diálogo, por isto, "Diálogos sobre Alfabetização de Jovens, Adultos e Idosos". É no encontro comigo e com o Outro que me constituo, nos ensinam os clássicos Karl Marx e Paulo Freire. A Alfabetização de Jovens, Adultos e Idosos é transcender as relações sociais que nos constituem e retornar à base. É, então, um movimento de perceber que lugar ocupo ou devo ocupar no tempo presente para me constituir enquanto gente, humana, humano.

Assim, na experiência vivenciada no âmbito do componente em pauta os sujeitos clássicos da educação de Jovens, Adultos e Idosos, ou seja, docentes e discentes são ressignificados, são reconstruídos na direção do ser, ao me tornar gente, gente no mundo, a relação passa a materializar a ponte que nos liga ao Outro social, o "aluno". Esse sujeito dos manuais de didática ou das obras da sociologia, da psicologia passa a ser minha mãe, meu pai, minha avó, avô, tio, tia, vizinha... Opa! E agora? Destituída a relação docente-discente clássica (o professor-aluno, tal como nos velhos manuais), eis que surge agora uma relação entre "gentes" em processo de humanização.

A educação popular ganha então vida, ela me refaz no processo abstrato e me torna ser ativo em uma relação com o Outro, também ativo, também cheio de histórias, memórias, cheiros, jeitos, sabores. Ele e Ela também sou Eu.

$\mathrm{Eu}$, filha e filho de trabalhadores; Eu estudante das escolas noturnas; Eu a trabalhadora e trabalhador que borrou muitos livros com suor e lágrimas por não

Educação, Psicologia e Interfaces, Volume 4, Número 1, p. 64-75, Janeiro/Março, 2020. 
compreender o texto; Eu filha e filho de retirantes, desenraizados, sem terra, sem teto, sem trabalho... O "Eu Nós".

A Educação Popular nos torna vivos dentro de uma Universidade que insiste em nos querer mortos. A Educação Popular nos torna gente em uma Universidade que insiste em nos querer coisa. A Educação Popular nos torna humanos, em uma Universidade que insiste em nos querer máquinas produtivas.

\section{RESULTADOS E DISCUSSÕES}

Diante de toda abordagem apresentada e considerando as problematizações discutidas, torna-se relevante apresentar alguns dados da experiência vivenciada, os quais possibilitaram impactos bastante positivos, ultrapassando as expectativas iniciais e fomentaram novas demandas para continuidade da proposta. Nas duas edições de oferta do componente, houve grande demanda dos estudantes. Foi necessária a articulação de uma sala mais ampla, a fim de comportar maior número de estudantes, sem, portanto, comprometer a qualificação das discussões e reflexões em sala, bem como, o acompanhamento e orientação na construção do trabalho final. Na primeira edição foram matriculados 68 (sessenta e oito) estudantes, sendo que destes 61(sessenta e um) foram aprovados. Na segunda edição, foram inseridos 50 (cinquenta) discentes (limite definido pelas professoras) dos quais 46 (quarenta e seis) deles foram aprovados. Os dados evidenciam a grande relevância de fortalecer o diálogo sobre a alfabetização de jovens, adultos e idosos e nos convidam a continuidade da oferta para que as problematizações sejam ampliadas para um maior número de estudantes em processo de formação inicial. Em apenas duas edições, as reflexões provocadas pelo componente já conseguiram alcançar um total de 107 (cento e sete) estudantes, os quais poderão ampliar o debate em outros movimentos e cenários para além da Universidade.

A partir das abordagens teórico-metodológico-conceituais inseridas na unidade temática, adotamos estratégias didáticas que buscassem valorizar a dinâmica relacional e a troca de experiências com vistas à construção colaborativa do conhecimento. Assim, a preocupação foi em romper com a dicotomia teoria/prática e ensino/pesquisa, apostando em uma ação metodológica em que os referidos campos dialogassem em

Educação, Psicologia e Interfaces, Volume 4, Número 1, p. 64-75, Janeiro/Março, 2020.

ISSN: 2594-5343. DOI: https://doi.org/10.37444/issn-2594-5343.v4i1.181 
todas as propostas apresentadas. Dessa forma, conforme já mencionado, teoria/prática, ensino/pesquisa estiveram em constante consonância e apresentaram-se de forma interdependente e indissociável nos mais diversos os momentos formativos, sobretudo na produção da atividade final que exigiu dos participantes lançarem mão das reflexões teórico-conceituais estudadas para a produção do trabalho prático que constituiu na pesquisa e edição de um vídeo documentário com pessoas (jovens, adultas ou idosas) sobre o seu processo de alfabetização.

Depois de um longo processo formativo, envolvendo diversas problematizações, estudos e produções, foi necessário estender as ações no âmbito do ensino e da pesquisa e articular os resultados desse processo de estudo e investigação com a extensão acadêmica, a fim de envolver não apenas os estudantes de Pedagogia, mas toda a comunidade interna interessada, além da comunidade externa e pesquisadores da área. Foi na perspectiva de um maior alcance das pesquisas e reflexões que dois seminários temáticos foram realizados, sendo um no final de cada edição da unidade temática. Da primeira edição, foi fomentada a realização do Seminário de Extensão intitulado "Reflexões sobre alfabetização e processos de emancipação humana: leitura de mundo, leitura de si” e, da segunda edição, o Seminário "Diálogos sobre alfabetização de jovens, adultos e idosos: perspectivas e enfrentamentos", com a intenção de promover um amplo debate acerca da temática em pauta, envolvendo estudantes das licenciaturas, professores em exercício na EJAI, sociedade civil, pesquisadores e demais interessados na temática.

Consideramos que a formação de educadores/alfabetizadores perpassa por diversos momentos de diálogos, reflexões e, sobretudo, de articulação com a Educação Básica e suas modalidades de ensino. Por isso é de extrema importância que sejam criados momentos em que os diferentes saberes dialoguem e se fortaleçam. Não acreditamos em processos universais e neutros, mas sim, em processos colaborativos e sustentados em bases sólidas para que haja o fortalecimento e qualificação das práticas.

Os referidos eventos foram realizados como ações do Núcleo de Ensino, Pesquisa e Extensão em Alfabetização e Educação Popular, vinculado ao Programa de Extensão Tecelendo, do Centro de Formação de Professores, da Universidade Federal do Recôncavo da Bahia e tiveram como foco as reflexões acerca da Alfabetização de

Educação, Psicologia e Interfaces, Volume 4, Número 1, p. 64-75, Janeiro/Março, 2020.

ISSN: 2594-5343. DOI: https://doi.org/10.37444/issn-2594-5343.v4i1.181 
Jovens, Adultos e Idosos e nos seus processos emancipatórios, bem como nas perspectivas e enfrentamentos a partir do lugar que ocupa no contexto atual.

Os referidos eventos de extensão objetivaram, dentre outros aspectos, contribuir de forma reflexiva e colaborativa com o processo formativo dos estudantes do curso de Pedagogia e profissionais da Educação Básica no âmbito da Educação de Jovens, Adultos e Idosos; promover um amplo debate acerca das experiências vivenciadas no processo de escuta e pesquisa junto aos sujeitos jovens, adultos e idosos e seus processos emancipatórios de alfabetização e promover a integração e firmar parcerias da Universidade com a comunidade, através de debates colaborativos.

Nas duas edições do Seminário de Extensão houve boa participação, tanto da comunidade interna, como externa. No primeiro, foram credenciados 75 (setenta e cinco) participantes na categoria de estudante e 04 (quatro) na categoria de docente, totalizando 79 (setenta e nove) participantes. Já no segundo evento foram credenciados 63 (sessenta e três) participantes da comunidade interna, sendo 56 (cinquenta e seis) estudantes, 4 (quatro) estudantes de pós-graduação, 03 (três) docentes, e, na comunidade externa, 28 (vinte e oito) participantes, sendo 04 (quatro) de outras instituições de Ensino Superior e 24 (vinte e quatro) da comunidade geral, totalizando 91 (noventa e um) participantes credenciados.

Estes dados apresentados, somados as reflexões anteriormente tecidas, evidenciam a relevância da temática, sobretudo sendo realizada numa perspectiva emancipatória, problematizadora e partindo dos sujeitos com provocações para que sejam percebidos nesse processo.

Os resultados apresentados nos convidam a fortalecer o debate no âmbito acadêmico, sobretudo quando se referem aos cursos de formação de professores, assim como nos provocam a militar cada vez mais na luta pelo direito à educação e à alfabetização na perspectiva da Educação Popular de modo que possa garantir o processo de Formação Humana.

Os dados e impactos observados nos convidam também a pensar nos sujeitos inseridos na Educação de Jovens, Adultos e Idosos, nas suas trajetórias truncadas, com marcas históricas de exclusão e negação de direitos. É nessa perspectiva contrahegemônica que precisamos avançar. E este debate da alfabetização como um direito 
precisa ser fortalecido como forma de resistência aos retrocessos provocados no momento atual.

\section{4. (IN)CONCLUSÕES: NOTAS PARA O RECOMEÇO}

Depois de todas as reflexões aqui tecidas, os dados nos autorizam afirmar que os impactos da experiência vivenciada ultrapassaram os limites da Universidade, contemplando outros espaços, por meio de um trabalho alicerçado no diálogo e na colaboração, partindo dos sujeitos em um estrito processo de humanização.

Através de uma prática viva, priorizando a perspectiva crítica de educação, em prol da alfabetização da classe trabalhadora, a experiência em pauta se constituiu como um movimento de busca para compreender o lugar ocupado pela educação de pessoas jovens, adultas e idosas e lugar que devo ocupar para me constituir enquanto sujeito do processo, enquanto ser humano, enquanto gente.

Assim, a experiência vivenciada no âmbito do componente provocou impactos positivos, reveladas nas expressões e narrativas dos sujeitos inseridos no processo. Muitas histórias narradas, pensamentos revelados e lágrimas que evidenciaram a implicação dos participantes. Nestes momentos a educação ganha vida e pulsa ao reconhecer que as trajetórias de negação de direitos estão presentes na vida de cada um e cada uma enquanto classe trabalhadora. Se perceber neste lugar de negação e buscar estratégia de luta e resistência para sair desse lugar por meio de uma ação coletiva de emancipação, consideramos o ponto fundante da experiência.

Esperamos que esta ação possa contribuir para fomentar novas discussões e pesquisas, além da ampliação do debate de um processo alfabetizador comprometido com as pessoas jovens, adultas e idosas não alfabetizadas, sobretudo com olhar voltado para a redução da injustiça social por meio de um processo que dialogue com os princípios da Educação Popular, voltado para a formação humana.

\section{Notas de rodapé}

${ }^{1}$ A concepção de educação defendida neste trabalho está pautada nas ideias de Freire, ou seja, enquanto processo constante de criação do conhecimento e de busca da transformaçãoreinvenção da realidade pela ação-reflexão humana.

\section{REFERÊNCIAS BIBLIOGRÁFICAS}

Educação, Psicologia e Interfaces, Volume 4, Número 1, p. 64-75, Janeiro/Março, 2020.

ISSN: 2594-5343. DOI: https://doi.org/10.37444/issn-2594-5343.v4i1.181 
BENINCÁ, Elli. O senso comum pedagógico: práxis e resistência. 2002. Tese (Doutorado em Educação) - Faculdade de Educação, Universidade Federal do Rio Grande do Sul, Porto Alegre, 2002.

FREIRE, Paulo. Ação Cultural para a Liberdade: e outros escritos. Rio de Janeiro: Paz e Terra, 2003.

FREIRE, Paulo. Pedagogia da esperança: um reencontro com a pedagogia do oprimido. Notas: Ana Maria Araújo Freire. Rio de Janeiro: Paz e Terra, 1992.

GARCÍA, Águeda Mayra Pérez y coautores. Una Proposicíón de Alfabetización: desde posiciones de gênero y ruralidad. Cuba: Editorial Pueblo y Educación, 2007.

GIROUX, Henry. A escola crítica e a política cultural. 3. ed. São Paulo: Cortez: Autores Associados, 1992.

\section{Credenciais da/os autora/es}

ANDRADE, Maria Eurácia Barreto de. Professora na Universidade Federal do Recôncavo da Bahia (UFRB), Doutora em Educação (UA). E-mail: mariaeuracia@ufrb.edu.br

FREITAS, Gilselia Macedo Cardoso. Professora na Universidade Federal do Recôncavo da Bahia (UFRB), Doutora em Educação (UDELMAR). E-mail: gfreitas@ufrb.edu.br

SANTOS, Andreia Barbosa. Professora na Universidade Federal do Recôncavo da Bahia (UFRB), Doutora em Educação (UFPB). E-mail: abarroca@ufrb.edu.br

Endereço para correspondência: Maria Eurácia Barreto de Andrade. Rua Nestor de Melo Pita S/N - Centro de Formação de Professores, Universidade Federal do Recôncavo da Bahia (UFRB). CEP: 45300-000 - Amargosa - Bahia. E-mail: mariaeuracia@ufrb.edu.br

\section{Como citar este artigo (Formato ABNT):}

ANDRADE, Maria Eurácia Barreto; FREIRAS, Gilselia Macedo Cardoso; SANTOS, Andreia Barbosa. Diálogos sobre alfabetização de jovens, adultos e idosos no âmbito do CFP/UFRB. Educação, Psicologia e Interfaces, v. 4, n.1, p. 64-75, 2020. DOI: https://doi.org/10.37444/issn-2594-5343.v4i1.181

Recebido: 07/08/2019.

Aceito: 20/11/2019.

Educação, Psicologia e Interfaces, Volume 4, Número 1, p. 64-75, Janeiro/Março, 2020.

ISSN: 2594-5343. DOI: https://doi.org/10.37444/issn-2594-5343.v4i1.181 